\title{
Modeling snow instability with the snow-cover model SNOWPACK
}

\author{
Mighael LeHning,${ }^{1}$ Charles FierZ, ${ }^{1}$ Bob BroWn, ${ }^{2}$ Bruge JAMiesON ${ }^{3}$ \\ ${ }^{1}$ WSL Swiss Federal Institute for Snow and Avalanche Research SLF, Flüelastrasse 11, CH-7260 Davos-Dorf, Switzerland \\ E-mail: lehning@slf.ch \\ ${ }^{2}$ Department of Civil Engineering, Room 214 Cobleigh Hall, Montana State University-Bozeman, MT 59717-3900, U.S.A. \\ ${ }^{3}$ Department of Civil Engineering, 2500 University Drive NW, University of Calgary, Calgary, Alberta T2N 1N4, Canada
}

\begin{abstract}
SNOWPACK has been in operational use for five consecutive winters on approximately 100 automatic weather stations in the Swiss Alps. It calculates snow precipitation, snowdrift and the layered structure of the snow cover. An analysis routine has been implemented that gives a stability estimation for a model profile. We distinguish between slab instability and direct action or deformation-rate instability. Slab instability relies on a static force balance within the snowpack (stability index) and may be used to assess stability for both natural and skier-triggered slab avalanches. We heuristically improve the slab index by adding a term of overload correction for all grain types and scaling the stability index with the bond size. Deformation-rate instability means that the load of the snow cover increases faster than the snow gains strength. An index is formulated based on the snow deformation rate. It may be associated with large snowfall events and wet-snow situations as they occur in catastrophic situations, or with the effect of a sudden increase in temperature. The results of both stability indices are compared to the forecasted avalanche danger. The indices are able to recognize cases of avalanching. It is shown that the inclusion of several locations, for which the indices are calculated, improves the correlation between stability indices and avalanche danger. A sufficient number of profiles could bridge the gap between snow-cover characteristics at a point and avalanche danger.
\end{abstract}

\section{INTRODUCTION}

A deterministic prediction of individual avalanches is still impossible. Therefore, avalanche warning is done using a danger level or danger degree, which describes the probability of avalanche triggering and the expected number of avalanches of a given size range in an area. On the other hand, snow research has shown that some snow types or layers are more likely to cause avalanches than others. Avalanche forecasters rely on snow-profile interpretation as one of many sources of information to judge the stability of a snow cover (Schweizer and Wiesinger, 2001). However, a single snow profile gives only very limited information on the probability of an avalanche for a slope and even less for a region. When the snow profile is combined with a stability test (rutschblock, stuff block, etc.), important additional information is gained (Föhn, 1987). But due to a high spatial variability of the snow cover, a direct link to avalanche danger cannot be established. This is only possible if a "sufficient" number of profiles and stability tests are evaluated for a given area. The sufficient number is still the subject of intense debate.

Gathering snow profiles is a difficult, time-consuming and often impossible (because of the avalanche danger) task; a possible solution is to use simulated snow profiles. However, relating modeled snow-cover properties to snow stability is also problematic because the stability of the snow cover cannot be deduced unambiguously from stratigraphy only. The French SAFRAN-Crocus-MÉPRA (SCM) chain
(Durand and others, 1999) led the way to operational snowcover modeling and combined the results of a snow-cover simulation with the expert system MÉPRA (Giraud and Navarre, 1995) to give a stability interpretation of the model profiles. MÉPRA is based on a classical stability-index approach (Föhn, 1987), which is combined with a set of rules to evaluate the profile in terms of stability classes. Since the simulated snow covers are for a range of altitudes and expositions on hypothetical pyramids (Durand and others, 1999), this method has the potential to relate individual snow profiles to the local or regional avalanche danger. However, avalanche danger by itself is very difficult to validate, so a quantitative evaluation of the success rate of the method is even more problematic.

Our contribution explores the link between individual snow profiles and avalanche danger by using stability criteria applied to modeled snow profiles. The Swiss snow-cover model SNOWPACK (Bartelt and Lehning, 2002; Lehning and others, 2002a,b) is successfully used to operationally assess new snow precipitation, drifting snow and snow-cover development at approximately 100 automatic weather stations in the high-alpine zone of the Swiss Alps. A good prediction of snow metamorphism and surface hoar formation (Lehning and others, 2002a,b) allows weak-layer development to be simulated with reasonable accuracy. Therefore, we now try to calculate a stability estimate from the modeled snow profile. This is a first step and contribution to overcome the gap between the common practice of making a snow-cover assessment on the one hand and the need to 
Table 1. Parameters and coefficient of statistical regression model for shear (Daniel's) strength of buried surface hoar

\begin{tabular}{|c|c|c|c|c|}
\hline \multirow[t]{2}{*}{ Variable } & \multirow[t]{2}{*}{ Description } & \multicolumn{2}{|c|}{ Coefficient } & \multirow[t]{2}{*}{ Unit } \\
\hline & & $\begin{array}{l}\text { Chalmers and } \\
\text { Jamieson } \\
\text { (2001) }\end{array}$ & $\begin{array}{c}\text { New without } \\
E_{\min }\end{array}$ & \\
\hline (intercept) & & 0.336 & 0.429 & $\mathrm{kPa}$ \\
\hline$t$ & $\begin{array}{l}\text { Time since burial in } \\
\text { days }\end{array}$ & 0.0139 & 0.0138 & $\mathrm{kPad}^{-1}$ \\
\hline$\sigma$ & $\begin{array}{l}\text { Vertical load of slab } \\
(\mathrm{kPa})\end{array}$ & 1.18 & 1.12 & \\
\hline$H$ & $\begin{array}{l}\text { Vertical depth of } \\
\text { overlying slab }(\mathrm{cm})\end{array}$ & -0.00625 & -0.00596 & $\mathrm{kPa} \mathrm{cm}^{-1}$ \\
\hline$H_{\mathrm{s}}$ & Snow depth $(\mathrm{cm})$ & 0.000804 & 0.000785 & $\mathrm{kPa} \mathrm{cm}^{-1}$ \\
\hline Thick & $\begin{array}{l}\text { Thickness of weak } \\
\text { layer }(\mathrm{cm})\end{array}$ & -0.287 & -0.271 & $\mathrm{kPa} \mathrm{cm}^{-1}$ \\
\hline$T_{\mathrm{wl}}$ & $\begin{array}{l}\text { Temperature of weak } \\
\text { layer }\left({ }^{\circ} \mathrm{C}\right)\end{array}$ & 0.0187 & 0.0202 & $\mathrm{kPa}^{\circ} \mathrm{C}^{-1}$ \\
\hline$E_{\min }$ & $\begin{array}{l}\text { Min. grain-size in } \\
\text { weak layer }(\mathrm{mm})\end{array}$ & 0.0204 & & $\mathrm{kPa} \mathrm{mm}^{-1}$ \\
\hline
\end{tabular}

judge avalanche danger on the other hand. At this stage, the analysis is confined to flat-field profiles at our Interkantonales Mess- und Informationssystem (IMIS) automatic weather stations. Clearly, this approach does not yet consider the full variability of snow-cover development at slopes of different exposures. However, a recent publication (Chalmers and Jamieson, 2001) shows that it is possible to relate flatfield snow-profile characteristics to local avalanche danger, at least for the rather simple case of a widespread buried surface-hoar weakness in a continental climate.

One basis of the implementation presented here is the classical stability-index approach. New data on shear strength (e.g. of buried surface hoar) are used. In addition, a deformation-rate stability criterion is given. This approach is novel and is expected to be useful for new-snow and wet-snow avalanches. In the next section, we describe the SNOWPACK stability index. We then discuss its performance during winter 2002/03. Finally, improvements are suggested, based on the microstructure snow characteristics as provided by SNOWPACK.

\section{SNOWPACK STABILITY MODEL}

As a first approach, the classical stability index for natural avalanches and skier-triggered avalanches is calculated for each SNOWPACK layer. These two indices are supplemented by an index based on the deformation rate. The SNOWPACK graphical user interface (SN_GUI) outputs the minimum values for the snow profile and shows the depths of the instabilities. Note that the minimum is only searched for below a certain slab depth $(10 \mathrm{~cm})$ and above a certain "roughness" height $(20 \mathrm{~cm})$. The search range for the skier index is additionally confined to depths of $10-120 \mathrm{~cm}$. The stability information is called an index because the true mechanism of fracture propagation in snow is not modeled. All indices used here indicate instability for values $<1$ and stability for values $>1.5$.

\section{Static stability index}

The stability index has been implemented in the most recent form as described in detail by Jamieson and Johnston (1998), which is based on the work of Roch (1966) and Föhn (1987). The index is the fraction between the snow shear strength (critical snow shear stress) and the actual shear stress exerted either just by the snow itself or by the snow and a skier. The critical stress is determined by the Daniel's strength plus a correction term that increases with increasing snow loading (Jamieson and Johnston, 1998). Values of the Daniel's strength are parameterized following Jamieson and Johnston (2001). The parameterization is based on density and grain type only and therefore makes no use of the SNOWPACK microstructure quantities. Therefore, based on new field data (Chalmers and Jamieson, 2001), we introduce a refined parameterization for buried surface hoar. The strength is given as a linear function of several snow parameters. The parameters and coefficients are summarized in Table 1. Table 1 gives the original values from Chalmers and Jamieson (2001) and our re-analysis after eliminating the variable "minimum grain-size". It is necessary to treat surface hoar separately because the densitydependent formulations for the other grain types would not work for thin surface-hoar layers, where only ambiguous density values can be determined. Furthermore, surface hoar is one of the most frequent failure layers, so the newly available data are highly welcome.

\section{Deformation-rate stability index}

The two static stability indices represent the strength-toforce ratio for a separated column of snow. They neglect that the strength of snow depends on the deformation rate. Therefore, an additional stability index is proposed, which is based on the deformation rate of the snow layers. This index still does not include the full physical basis of avalanche formation, which would involve the description of fracture propagation in a three-dimensionally varying snow cover and eventually the tension failure at the avalanche crown. However, the deformation-rate analysis is expected to describe the situation of new-snow avalanches as well as wet-snow avalanches better than the static stability indices. It also benefits from the microstructure treatment of snow in SNOWPACK (Lehning and others, 2002a) because the deformation rate is determined by the grainand bond sizes directly.

For the strain-rate-dependent critical stress in the bonds (or necks) of the snow matrix, we use a simplified form of the Nadreau and Michel (1986) criterion. Their criterion for failure has been tested for strain rates in ice ranging from $10^{-6}$ to as high as $10^{-3} \mathrm{~s}^{-1}$. This translates into snow strain rates approximately an order of magnitude smaller, which covers the range of snow strain rates of interest. The failure criterion takes into account the effect of pressure on the melting point of ice. Let $\sigma_{\mathrm{c}}$ be the critical stress in the necks at which the necks will fail. The failure criterion is then:

$$
\sigma_{\mathrm{c}}=-p_{\mathrm{h}} \tan \phi \sqrt{1-\frac{p_{\mathrm{h}}}{p_{\mathrm{h}}-\sigma_{0}}} .
$$

In the equation, $p_{\mathrm{h}}$ is the (negative) hydrostatic pressure that induces melting, $\sigma_{0}$ is the brittle fracture stress of ice and $\phi$ is the strain-rate-dependent function which 

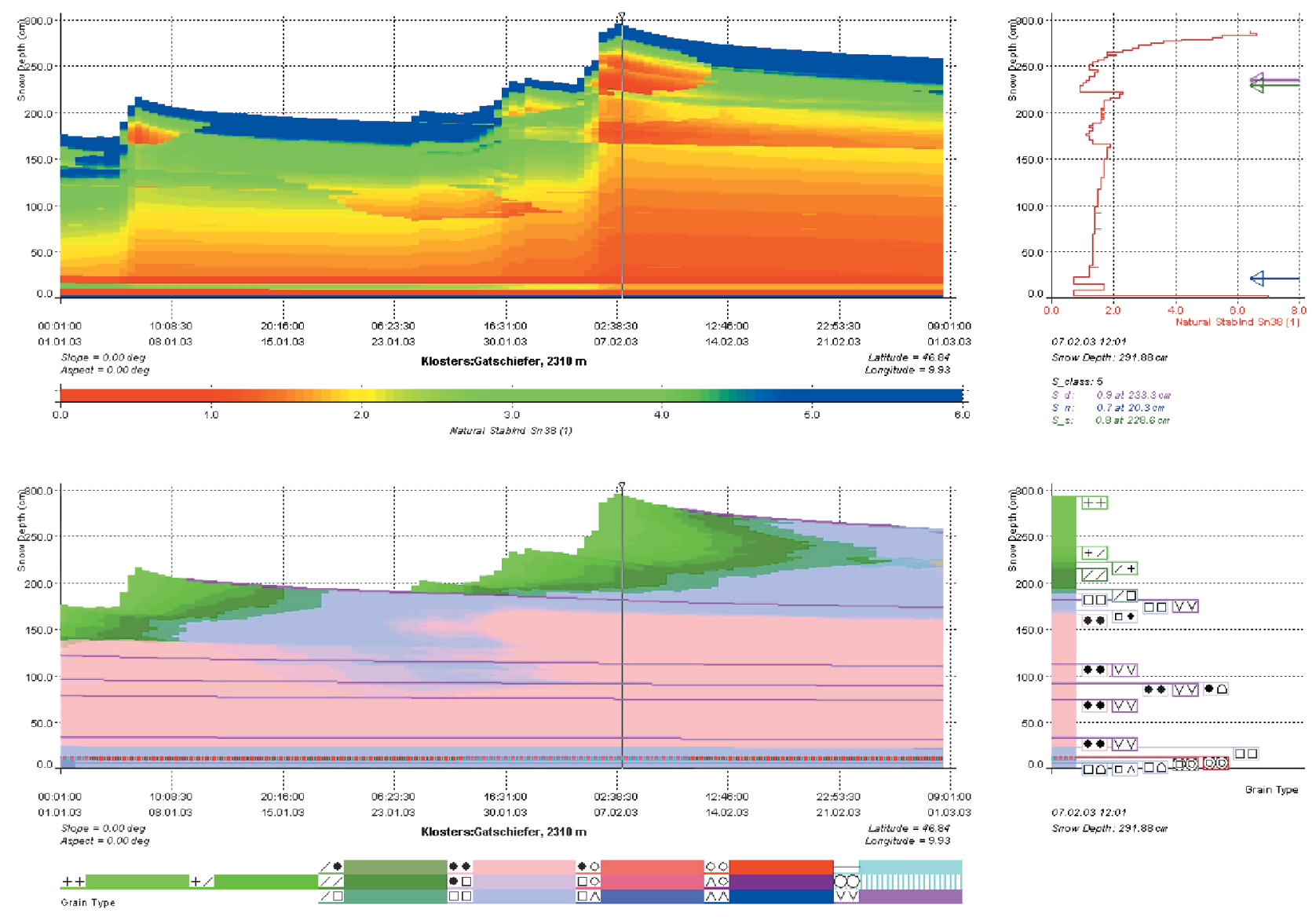

Fig. 1. Time development of the natural stability index and grain types for the IMIS station Klosters Gatschiefer in JanuaryFebruary 2003. The time development is shown for each snow layer and is colour-coded. At the marker position, the corresponding profile is given at the righthand side of the graph. For stability, not only is the stability index profile given but also the minimum is marked by an arrow (blue for natural index). Two additional arrows give the locations of the two remaining stability indices (deformation rate in pink, and skier in green). The minimum index values and their height are also written below the profile graph. The number for the stability class (S_class: 5) is meaningless in this graph. The stability class estimation is not yet implemented.

determines the shape of the failure surface. The parameters are determined according to Nadreau and Michel (1986):

$$
\begin{aligned}
\sigma_{0} & =10^{7} \mathrm{~Pa} \\
p_{\mathrm{h}} & =\left(-6.6 \times 10^{9}\right)+6.1 \times 10^{7} T_{\mathrm{C}}-\left(1.3 \times 10^{5} T_{\mathrm{C}}^{2}\right)(\mathrm{Pa}) \\
\phi & =70\left|\dot{\varepsilon}_{\mathrm{n}}\right|^{0.23} .
\end{aligned}
$$

In these empirical parameterizations, $T_{\mathrm{C}}$ is the temperature of ice in ${ }^{\circ} \mathrm{C}$ and $\dot{\varepsilon}_{\mathrm{n}}$ is the deformation rate in the bonds between the snow grains. The calculation of this deformation rate is developed in Lehning and others (2002a). The final deformation-rate stability index is then given by:

$$
S_{\mathrm{dr}}=\frac{\sigma_{\mathrm{c}}}{\sigma_{\mathrm{n}}}
$$

which is the ratio between the critical stress in the bonds or necks and the actual neck stress, $\sigma_{\mathrm{n}} . \sigma_{\mathrm{n}}$ is related to the snow overburden as detailed in Lehning and others (2002a).

\section{RESULTS AND DISGUSSION}

The instability model has been incorporated into the SNOWPACK operational model chain. First experiences have been obtained for winter 2002/03. In the following, we present results for selected periods from this winter to illustrate the typical behavior of the stability model.

\section{Discussion of preliminary stability results for the IMIS station Klosters Gatschiefer}

SNOWPACK has been mostly validated against data collected at our experimental site Weissfluhjoch Versuchsfeld (Lehning and others, 2002b). In the past two winters, data have also been collected at IMIS stations in the vicinity, so we now choose different locations, starting with the station Klosters Gatschiefer at $2310 \mathrm{~m}$ altitude. The station has more influence from the north and is thought to be representative for the situation north of the Davos area. Figure 1 presents the stability results for that station for JanuaryFebruary 2003 together with the grain type representation. The time marker is set at 7 February, when the avalanche danger increased to the level "high" (4, according to the European avalanche danger scale; see also Fig. 5) and many avalanches including large-scale ones were observed. The righthand side of the figure shows the respective stability grain-type profiles for that date. The figure has been produced from the SNOWPACK SN_GUI.

The profile information presented in Figure 1 is for the natural stability index. On the right of the graph, minimum values and the location of these minima for the remaining two indices are also given to allow easy comparison.

For the critical situation of 7 February, all three indices give values $<1$ and indicate instability. The deformationrate and skier indices locate the instability at the surface 

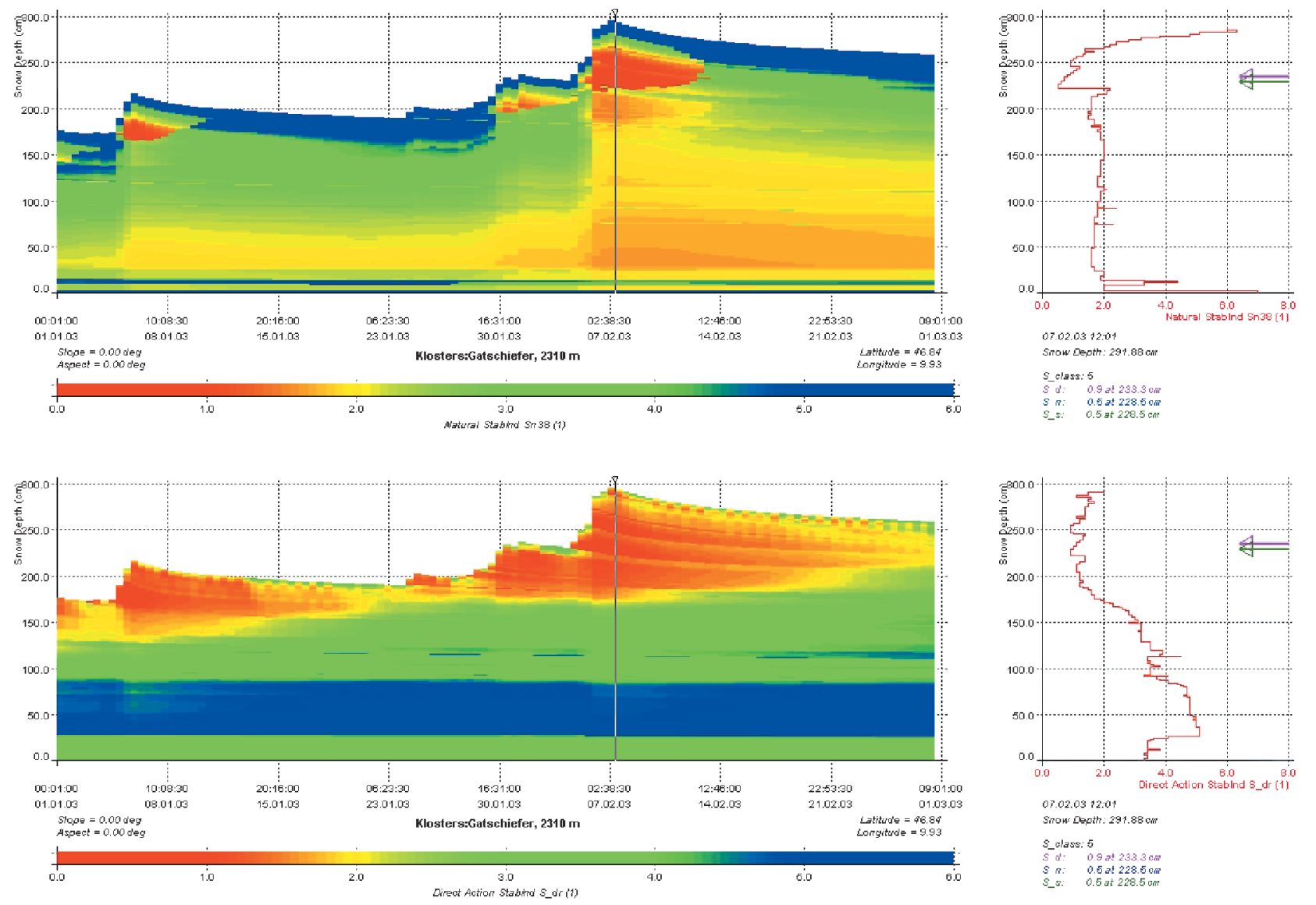

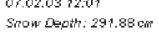

(5)

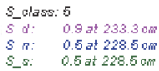

Fig. 2. Time development of natural and deformation-rate stability index as in Figure 1. For the natural stability index, an overload correction for all grain types and a bond-size scaling have been introduced.

below the most recent snowfall event. This corresponds to failure surfaces of observed avalanches and failure tests in the vicinity of the station.

However, the stability development of Figure 1 also shows features that are clearly inadequate. At present, the critical shear stress for both natural and skier indices is mainly a function of grain type and density. Furthermore, the stability index describes the situation for a separated column of snow and does not take into account threedimensional effects. Therefore, the natural stability index detects the weakest point in the profile in the layer of faceted crystals above the melt-freeze crust at $20 \mathrm{~cm}$ above the soil surface. The skier stability index finds the correct location of minimum stability because it is confined to the first $120 \mathrm{~cm}$ from the snow surface. It agrees with the deformation-rate index location of maximum weakness. This tendency of the natural stability index to diagnose maximum weakness close to the ground appears throughout the winter. This is because the increase in snow load exceeds the increase in estimated snow strength, which is a non-linear function of snow density only.

Another erroneous behavior is exhibited by the way stability changes due to metamorphic development. Following the long period of cloudless and cold weather in January, previously rounded grains (pink) become more faceted (blue) in the center of the snow cover. The snowfall events at the end of January cause the grains to become more rounded again afterwards. The development causes the stability first to decrease significantly and then to increase again. This is clearly in contradiction with observations. In the following, we will explore heuristically how to improve on these deficiencies.

\section{Suggestions to improve natural and skier stability indices}

While the deformation-rate stability index takes advantage of the advanced treatment of microstructure in SNOWPACK, the other two formulations are a function of the descriptive grain type and density only. Clearly, the bonding between grains could be used to reduce the error of increasing instability with depth of snow-layer burial. The bonds grow slowly during dry metamorphism and fast when melt processes become important (Lehning and others, 2002a). Nevertheless, the small changes in bond size during dry (kinetic growth or equi-temperature) metamorphism are expected to increase snow stability significantly. Therefore we explore the effect of scaling the natural and skier stability indices with the logarithm of bond size:

$$
S_{\mathrm{n}}=\frac{\Sigma_{\infty}+\sigma_{z z} \phi\left(\Sigma_{\infty}, \sigma_{z z}\right)}{\sigma_{x z}}\left[1-\frac{f}{2}+f \frac{\log \left(\frac{r_{\mathrm{b}}^{\min }}{r_{\mathrm{b}}}\right)}{\log \left(\frac{r_{\mathrm{b}}^{\min }}{r_{\mathrm{b}}^{\max }}\right)}\right] .
$$

Here $\Sigma_{\infty}$ is the shear (Daniel's) strength, $\sigma_{z z}$ is the normal load and $\sigma_{x z}$ is the shear force per unit area. The function $\phi\left(\Sigma_{\infty}, \sigma_{z z}\right)$ is a correction term describing the effect of overload on shear strength (Roch, 1966). The scaling term contains the scaling factor $f(1)$ the bond radius $r_{\mathrm{b}}$ and the minimum and maximum bond radiuses $r_{\mathrm{b}}^{\min }$ and $r_{\mathrm{b}}^{\max }$, respectively. Since the scaling will produce a new stability 

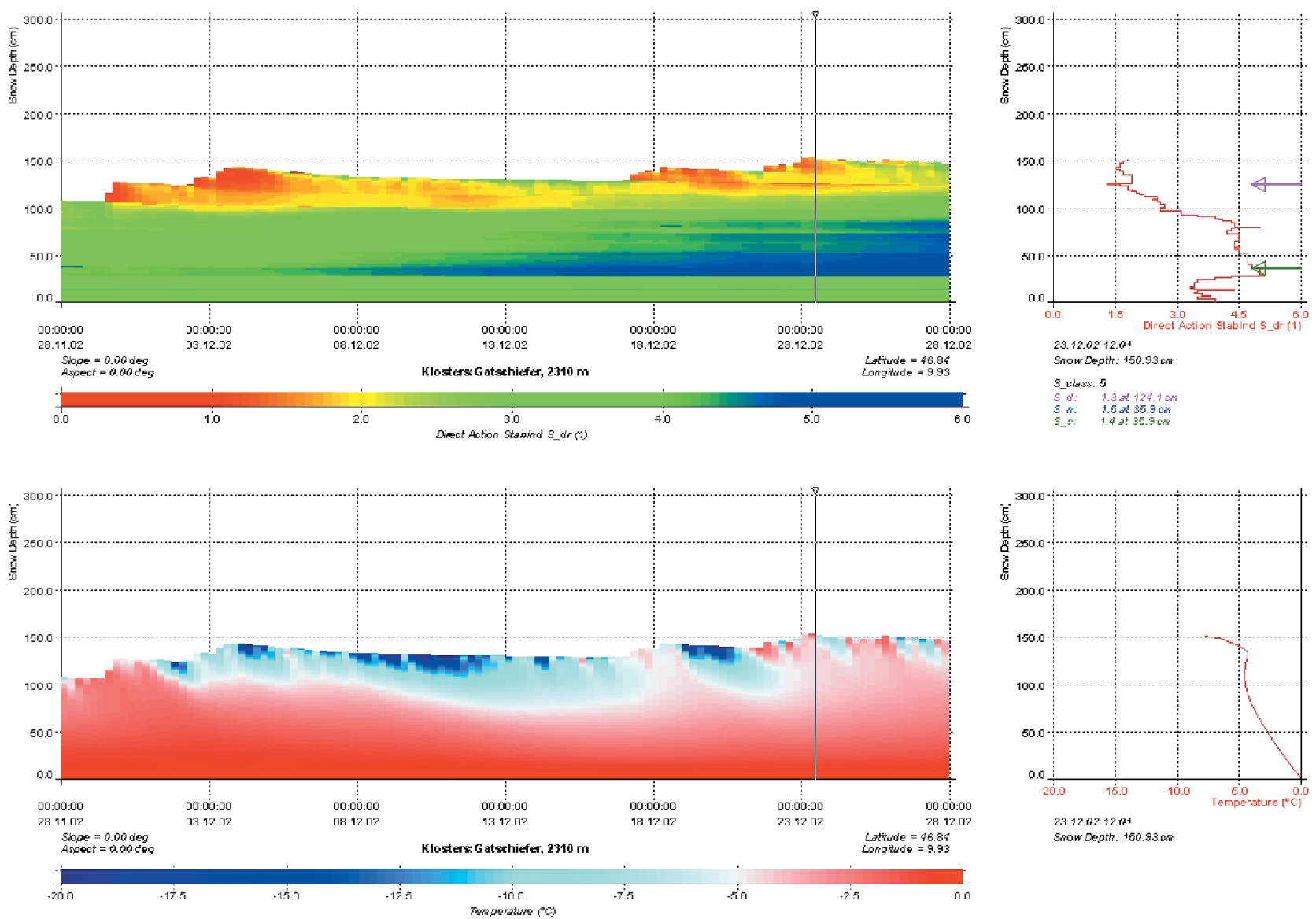

Fig. 3. Time development of deformation-rate stability index and temperature. Rising temperatures create a weak layer below the surface. On 23 December, avalanching has been observed in the area.

index with the range $\left[S_{\mathrm{n}}-f / 2 ; S_{\mathrm{n}}+f / 2\right]$, where $S_{\mathrm{n}}$ is the original index, the scaling factor can be used to determine the magnitude of the scaling. Figure 2 shows the result for $f=0.7$.

Jamieson and Johnston (1998) review formulations for the normal-load correction $\phi\left(\Sigma_{\infty}, \sigma_{z z}\right)$. In their figure 1, all grain types appear to show a similar shear strength dependency on normal load. Nonetheless, they use the normal-load correction only for fresh snow, decomposed particles and rounded grains. This restriction causes the erroneous behavior discussed above, that stability will decrease due to metamorphism and then increase again. Using a normal-load correction for all snow types will also help to limit the decrease of stability when moving to larger depths in the snow profile. We therefore suggest using the normal-load correction, which they suggest for decomposed particles and rounded grains,

$$
\phi\left(\Sigma_{\infty}, \sigma_{z z}\right)=0.08 \Sigma_{\infty}+0.224
$$

for all grain types, except for buried surface hoar because the new formulation of shear strength for surface hoar (Table 1) already contains an explicit dependency on normal load.

The two corrections discussed above are applied to both the natural and the skier stability indices. In the following we discuss results obtained with the adapted indices.

\section{Results with adapted formulations}

Figure 2 presents the development of the natural and deformation-rate stability indices. The deformation-rate index has not been changed. The bond-size scaling together with the introduction of the overload correction for all grain types (except surface hoar) has the desired effect that the natural stability index no longer shows the destabilization zone at the end of January in the middle of the snow cover due to kinetic metamorphism. Also, the tendency to show increasing instability for deeply buried snow layers is now reduced. For the critical situation of 7 February, all three stability indices indicate instability for the fresh snow layers.

Analyzing the behavior of the deformation-rate index, it becomes obvious that it mostly has minimum values at relatively recent snow layers close to the surface. The index is less specific than the more empirical static stability indices. For example, layers of buried surface hoar are not necessarily captured by this formulation. The index is constructed to pick up dynamic layers, where changes in the snow microstructure are taking place. The index correctly predicts that old and settled layers of snow are no longer dangerous. An example of its usefulness in new-snow situations is given in Figure 3. The deformation-rate stability index is shown, together with the temperature development for December, at Klosters Gatschiefer. One of the most difficult judgments for avalanche-warning experts is to what extent a sudden increase in temperature can destabilize the snow cover and lead to avalanches. In Figure 3 it can be seen that warming creates a distinct layer of high deformation at approximately $20 \mathrm{~cm}$ below the snow surface. This development starts following the warming period on 18/19 December. The following cooling phase makes the layer less active. With the snowfall of 23 December and the increase in temperature at the same time, the layer becomes active again. In this area, spontaneous slab avalanching has been observed following the snowfall and the warming. The 
Lehning and others: Modeling snow instability with the snow-cover model SNOWPACK

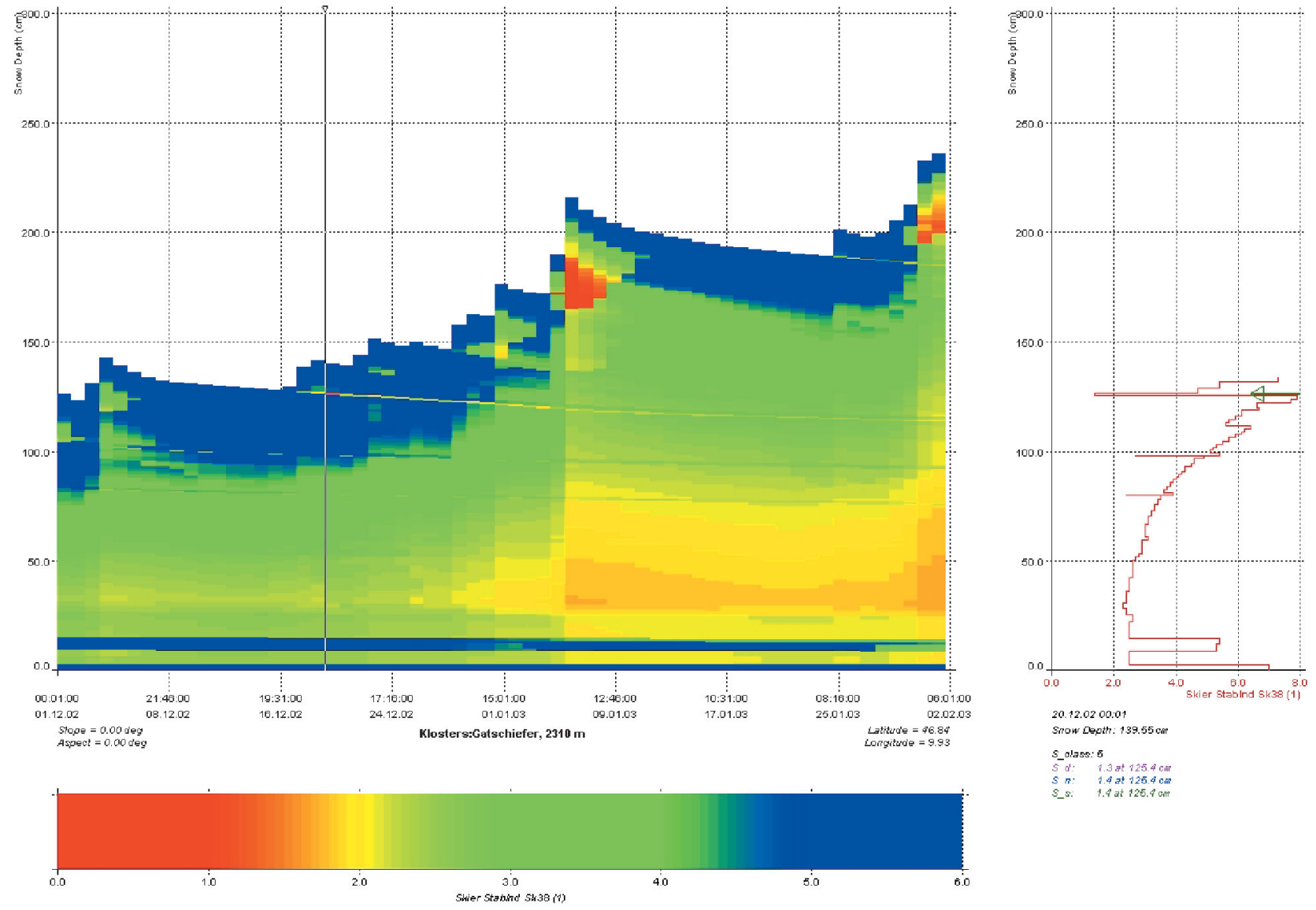

Fig. 4. Time development of skier stability index for December-Fanuary for Klosters Gatschiefer. The surface hoar formed during the period of fair weather in December creates a local instability when buried by fresh snow.

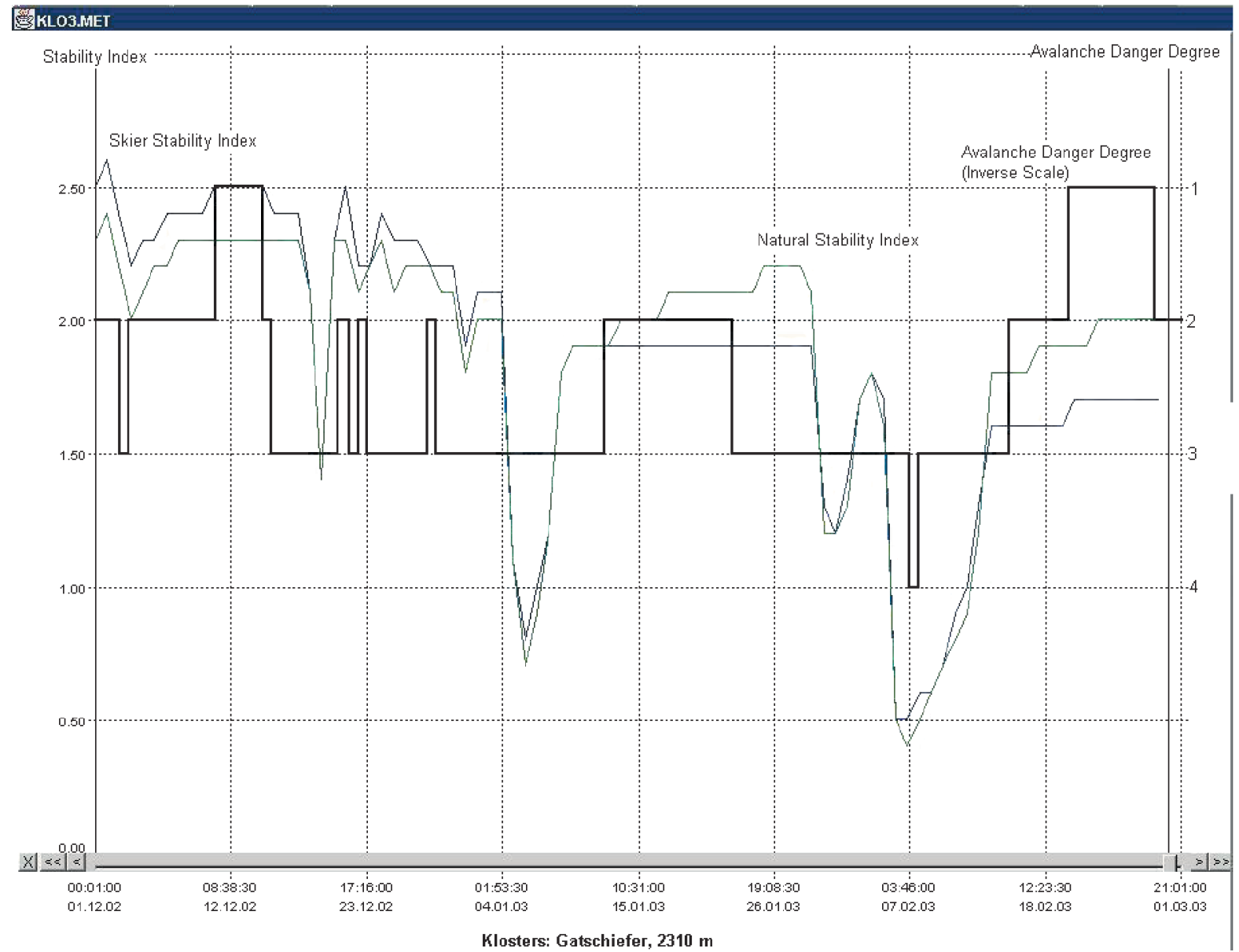

Fig. 5. Time series of minimum values of skier and natural stability indices in comparison with development of forecasted avalanche danger level for Klosters Gatschiefer ( $y$ axis inverted). Parts of the time series show a good correlation. 


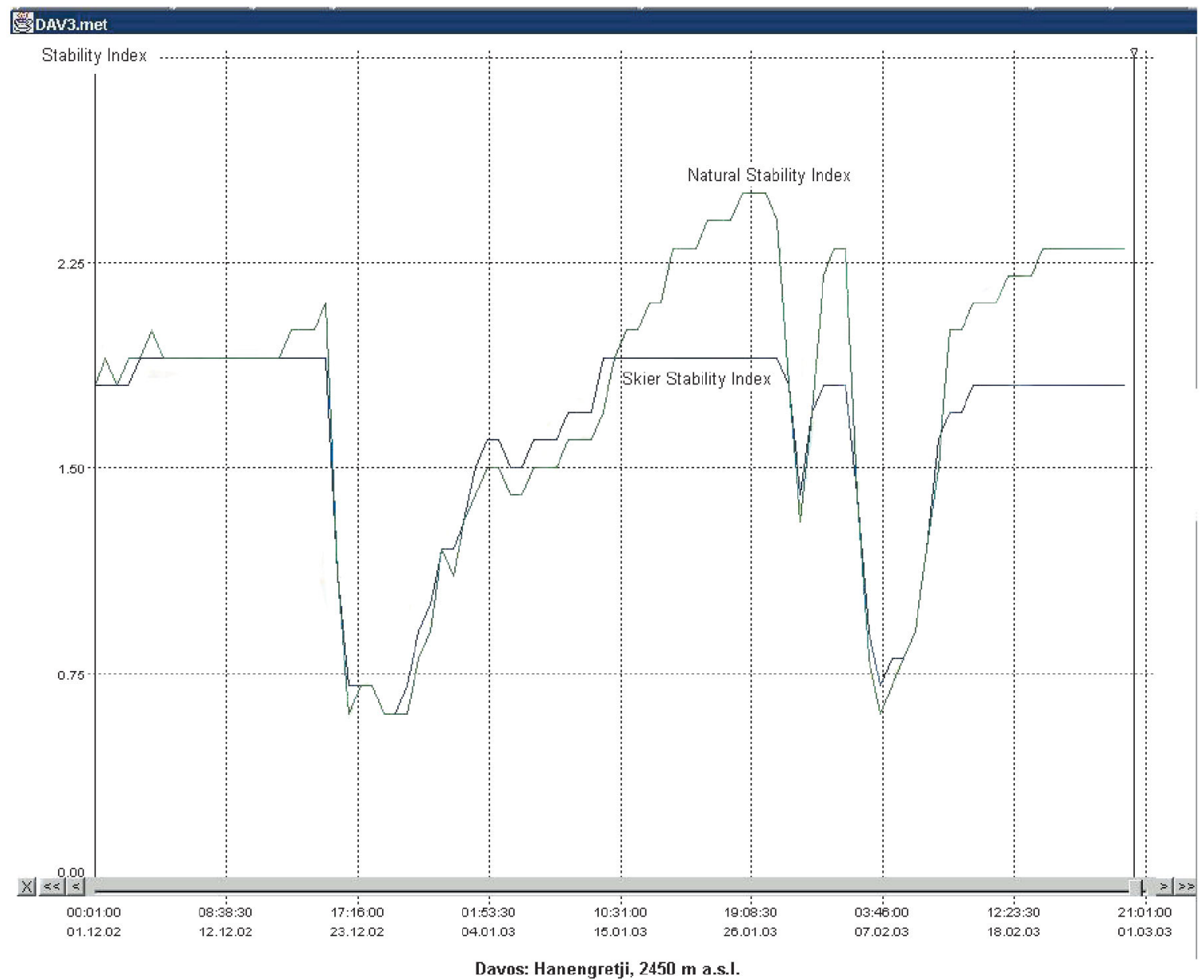

Fig. 6. Time series of minimum values of skier and natural stability indices for the IMIS station Davos Hahnengretji. The surface hoar layer produces a larger instability than for Klosters Gatschiefer.

failure layer corresponds to the layer found by the index, which gives an intermediate stability value of 1.3. Note that at the station Klosters Madrisa, on the opposite side of the valley, a similar development is observed (not shown).

In the previous subsection, surface hoar was mentioned as a possible problematic layer. In winter 2002/03, significant surface hoar was formed during a long period of cloudless weather between 5 and 16 December. This surface hoar was subsequently buried and was the primary weak layer for skier-triggered avalanches approximately until the snowfall events at the end of the first week of January. Figure 4 explores the skier stability index for this situation. The skier stability index gives a result almost identical to that given by the natural stability index (not shown). The profile drawn for 20 December shows that the buried surface hoar is the primary instability, even though the absolute value of the index, 1.4, is not very low. Two more local instabilities due to buried surface hoar are found in the profile below the primary instability. Note that these three surface-hoar instabilities are no longer present on 7 February (Fig. 2). In fact, the index shows a rapid increase of stability for the surface hoar (cf. also Fig. 5). By the beginning of January, the numerical value of the stability index has increased from 1.4 to 2. However, the buried surface-hoar layer remains a local instability in the profile (not shown).

The most interesting two situations of winter 2002/03 have been analyzed and an example of the effect of a sudden warming on the deformation-rate index has been discussed. Figure 5 gives the time-series representation of the minimum values of the skier and natural stability indices for the
IMIS station Klosters. For comparison, the avalanche danger level valid for the area is plotted on the same graph. Note that the degree of danger is plotted on an inverse axis to allow a better visual comparison to the stability index. Ideally, stability indices and the danger-level curve should be correlated. The visual inspection suggests a remarkable correlation. As discussed above, the most dangerous situations are recognized by our stability model. Other local minima of the stability index are not correlated with an increase in the danger level. For example, for the snowfall events starting at the end of January, a destabilization is predicted by the indices, while no corresponding general increase of the danger level was issued.

As a further example, the time series of stability indices at the IMIS station Davos Hanengretji are shown in Figure 6. The instability on 7 February is also clearly recognized at this station. The burial of the surface hoar layer produces a larger instability than at Klosters Gatschiefer. Also, this instability is slower to stabilize.

As discussed in the introduction, it cannot be expected that the danger level is closely related to the results of our stability index for individual IMIS stations. Therefore, we consider the stability results for four additional IMIS stations (Davos Bärentälli, Davos Parsenn, Weissfluhjoch Versuchsfeld and Klosters Madrisa) in the vicinity. All four stations give a clear indication of instability on 7 February. Only one of these four (Davos Bärentälli) indicates instability for the buried surface hoar. The third instability found at Klosters Gatschiefer, related to the snowfall events at the end of January, is not present at any of the other stations. 
These results indicate that the true situation is better represented by interpreting the results at all available stations.

\section{CONGLUSIONS}

First experiences with three stability indices have been gathered during winter 2002/03 in the Swiss Alps. The indices are based on either a static stability concept or a deformation-rate assessment. A scaling with snow bond size and an application of the overload correction for all snow types qualitatively improved the static stability indices. The indices were qualitatively compared to avalanche danger levels and observed avalanche activity. A very critical situation related to a snowfall event has been recognized by all three indices. An example has been discussed, in which the deformation-rate index reacted to a sudden increase in temperature following a snowfall event. The general correlation between changes in danger level and the stability-index prediction is less clear when analyzing the situation for one location only. Through an analysis of additional stations in the area, a clearer picture emerges: the critical situation is correctly diagnosed at all stations, while less critical situations produce low stability indices at some stations only.

These results are at present purely qualitative. A thorough statistical evaluation is difficult but will be attempted in the future based on stability tests performed at the IMIS stations. The gap between a local or regional avalanche danger level and stability results at a single station became apparent during our comparison at the IMIS station Gatschiefer. The inclusion of additional stations could help to overcome this gap.

The physical basis of the stability index must also be improved. For example, the effect of stabilizing crusts in the slab above a potential weak layer is not represented in the current formulation. While the standard approach used here, together with some heuristic corrections, produces encouraging results, the theoretical basis of such an analysis is weak. From the results, it appears that a promising approach is to combine elements of the static stability indices with the deformation-based stability assessment. While the static indices react on grain- type changes, the deformationrate index locates the dynamic areas in the snow cover and incorporates snow microstructure development.

\section{ACKNOWLEDGEMENTS}

We thank W. Ammann for his continuing support. This first attempt to implement a stability interpretation in SNOWPACK has benefited from discussions with many colleagues, especially P. Bartelt, P. Föhn, K. Kronholm, C. Pielmeier, J. Schweizer, T. Stucki and T. Wiesinger. Most of them also helped out with data and fieldwork. This work would not have reached the present state without the strong encouragement of T. Russi and J. Rhyner. We also thank R. Jordan and G. Giraud for their helpful reviews which improved the paper.

\section{REFERENGES}

Bartelt, P. and M. Lehning. 2002. A physical SNOWPACK model for the Swiss avalanche warning. Part I. Numerical model. Cold Reg. Sci. Technol., $35(3), 123-145$.

Chalmers, T. S. and J. B. Jamieson. 2001. Extrapolating the skier stability of buried surface hoar layers from study plot measurements. Cold Reg. Sci. Technol., 33(2-3), 163-177.

Durand, Y., G. Giraud, E. Brun, L. Mérindol and E. Martin. 1999. A computer-based system simulating snowpack structures as a tool for regional avalanche forecasting. F. Glaciol., 45(151), 469-484. (Erratum: 46(152), 2000, p. 173.)

Föhn, P. M. B. 1987. The stability index and various triggering mechanisms. International Association of Hydrological Sciences Publication 162 (Symposium at Davos 1986 - Avalanche Formation, Movement and Effects), 195-214.

Giraud, G. and J. -P. Navarre. 1995. MÉPRA et le risque de déclenchement accidentel d'avalanches. In Sivardière, F., ed. Les apports de la recherche scientifique à la sécurité neige, glace et avalanche. Actes de Colloque, Chamonix 30 mai-3 juin 1995. Grenoble, Association Nationale pour l'Etude de la Neige et des Avalanches (ANENA), 145-150.

Jamieson, J. B. and C. D. Johnston. 1998. Refinements to the stability index for skier-triggered dry-slab avalanches. Ann. Glaciol., 26, 296-302.

Jamieson, B. and C. D. Johnston. 2001. Evaluation of the shear frame test for weak snowpack layers. Ann. Glaciol., 32, 59-69.

Lehning, M., P. Bartelt, B. Brown, C. Fierz and P. Satyawali. 2002a. A physical SNOWPACK model for the Swiss avalanche warning. Part II. Snow microstructure. Cold Reg. Sci. Technol., 35(3), 147-167.

Lehning, M., P. Bartelt, B. Brown and C. Fierz. 2002b. A physical SNOWPACK model for the Swiss avalanche warning service. Part III. Meteorological forcing, thin layer formation and evaluation. Cold Reg. Sci. Technol., 35(3), 169-184.

Nadreau, J. -P. and B. Michel. 1986. Yield and failure envelope for ice under multiaxial compressive stresses. Cold Reg. Sci. Technol., 13(1), 75-82.

Roch, A. 1966. Les variations de la résistance de la neige. International Association of Scientific Hydrology Publication 69 (Symposium at Davos 1965 Scientific Aspects of Snow and Ice Avalanches), 86-99.

Schweizer, J. and T. Wiesinger. 2001. Snow profile interpretation for stability evaluation. Cold Reg. Sci. Technol., 33(2-3), 179-188. 